\title{
МЕТАГЕНОМНЫЙ АНАЛИЗ МИКРОБИОМА КИШЕЧНИКА И БИОХИМИЧЕСКИЙ СОСТАВ МЯСА БРОЙЛЕРОВ ПРИ ИСПОЛЬЗОВАНИИ РАСТИТЕЛЬНОГО ЭКСТРАКТА Quercus cortex В РАЦИОНАХ
}

\author{
В.А. БАГИРОВ 1 , А.С. УШАКОВ 1 , Г.К. ДУСКАЕВ ${ }^{2}$, О.В. КВАН ${ }^{2}$, \\ Ш.Г. РАХМАТУЛИН ${ }^{2}$, Е.В. ЯУШЕВА ${ }^{2}$, И.А. ВЕРШИНИНА ${ }^{2}$
}

На сегодняшний день использование антибиотиков в ветеринарии, а также в качестве стимуляторов роста в животноводстве считается основной причиной развития устойчивости бактерий к антибиотикам. Водные экстракты растительного происхождения могут обеспечить новые простые подходы к борьбе с патогенными бактериями. В этой связи ведется активный поиск естественных альтернативных источников противомикробных препаратов. Дикие растения считаются практически неограниченным источником фитохимических веществ. Кроме того, водные экстракты растительного происхождения могут обеспечить новые простые подходы к борьбе с патогенными бактериями. Высказываются предположения, что увеличение показателей роста бройлеров после добавления биоактивных веществ растительного происхождения может быть связано с улучшением микробного состава кишечника и метаболической функции. Для других растительных веществ характерно улучшение профиля ненасыщенных жирных кислот и аминокислот в мясе. Таким образом, чтобы получить более полную картину потенциального использования растительных экстрактов для профилактики или борьбы с бактериальными инфекциями, необходимо оценить активность растительных экстрактов в отношении микробиома кишечника сельскохозяйственных животных и птицы и качества получаемой продукции. Мы изучили влияние танинсодержащего экстракта коры дуба (Quercus cortex) на биохимический состав мяса цыплят-бройлеров и микробиом кишечника. Исследования проводили в Центре коллективного пользования научным оборудованием ФНЦ биологических систем и агротехнологий РАН (г. Оренбург) на цыплятах-бройлерах кроссам Смена 8 в 2019 году. Для экспериментов сформировали четыре группы 7-суточных цыплят (по $n=30$, всего 120 особей). Контрольная группа получала основной рацион (ОР); I опытная - ОР + экстракт Quercus cortex (1 мл/кг живой массы); II опытная - OP + экстракт Quercus cortex (2 мл/кг живой массы); III опытная - OP + экстракт Quercus cortex (3 мл/кг живой массы). Анализ химического состава мяса цыплят-бройлеров показал, что включение в рацион птицы экстракта коры дуба в дозе 1 мл/кг живой массы способствует улучшению качества мяса за счет большего содержания влаги, сырого протеина и золы с одновременным уменьшением количества сырого жира (на $27,3 \%, \mathbf{p} \leq \mathbf{0 , 0 1}$ ). Добавление экстракта коры дуба в рацион приводило к повышению содержания незаменимых аминокислот в мясе: по лизину - на 1,63-3,43\% (p $\leq 0,01)$, по лейцинуизолейцину - на $2,20-5,00 \%(p \leq 0,05)$, метионину - на $0,55-1,93 \%(p \leq 0,05)$, валину - на 1,06-1,95\% (p $\leq \mathbf{0 , 0 5})$, фенилаланину (I и II групп) - на $0,45 \%$ и $1,14 \%$ (p $\leq \mathbf{0 , 0 5})$, треонину (I и II группа) - на $1,07 \%(p \leq 0,05)$ и $1,82 \%(p \leq 0,01)$. Количество заменимых аминокислот в грудных мышцах цыплят-бройлеров относительно контроля также возрастало, причем максимальный рост показателя отмечали в группе с дозировкой экстракта коры дуба 2 мл/кг живой массы. В грудных мышцах цыплят-бройлеров из I и III групп активнее, чем контроле, аккумулировались ненасыщенные жирные кислоты (в частности, содержание пальмитолеиновой было соответственно на 1,0 и 0,7 \% больше; $\mathbf{p} \leq \mathbf{0 , 0 5}$ ). Эксперименты также показали, что дополнительное скармливание птице экстракта Quercus cortex (использованные рационы характеризовались различным содержанием танинсодержащих веществ) оказывает непосредственное воздействие на состав микрофлоры кишечника (в частности, на его слепой отдел). В первую очередь это влияние проявилось в отношении филумов Firmicutes и Bacteroidetes, что указывает на возможные изменения в обменных процессах у цыплят-бройлеров, например в резорбции энергии и деградации белков и полисахаридов. Численность бактерий филума Bacteroidetes повышалась в I и III группах в 3,96 и 2,10 раза относительно контроля (р $\leq 0,05)$, тогда как во II группе этих бактерий не обнаружили. Число представителей филума Firmicutes уменьшалось в 3,60 и 1,47 раза в I и III группах относительно контроля (p $\leq 0,05)$, но увеличивалось в 1,26 раза - во II группе $(p \leq 0,05)$. Таким образом, интенсификация процессов пищеварения в кишечнике бройлеров при применении экстракта коры дуба в дозировке 1-3 мл/кг живой массы в качестве биологически активной добавки к рациону приводила к повышению содержание аминокислот и ненасыщенных жирных кислот в тушках, что улучшает их потребительские качества.

Ключевые слова: микробиом, цыплята-бройлеры, экстракт коры дуба, жирнокислотный состав, аминокислотный состав.

* Исследования выполнены при финансовой поддержке РНФ (проект № 16-16-10048 П). 
На сегодняшний день использование антибиотиков в ветеринарии, а также в качестве стимуляторов роста в животноводстве считается основной причиной развития устойчивости бактерий к антибиотикам. Всемирная организация здравоохранения (BO3, WHO) создала список антибиотикорезистентных приоритетных патогенных микроорганизмов, требующих новых стратегий борьбы с инфекциями (1). В этой связи идет активный поиск естественных альтернативных источников противомикробных препаратов (2). Дикие растения считаются практически неограниченным источником фитохимических веществ (3). При оценке терапевтического потенциала растительных экстрактов против бактерий птицы обнаружена восприимчивость S. enteritidis $(63,64 \%)$ (4), P. aeruginosa $(81,81 \%)$ и E. coli $(27,27 \%)$ к экстрактам листьев Mangifera indica L. cv. Julie, Euadenia eminens Hook f. и коры Euadenia trifoliata (Vahl) Oliv. $(5,6)$. Водные экстракты растительного происхождения могут обеспечить новые простые подходы в борьбе с патогенными бактериями (7).

Некоторые авторы полагают, что повышение ростовых показателей у бройлеров после добавления активных компонентов растений может быть связано с улучшением микробного состава кишечника и метаболической функции $(8,9)$. Для других растительных веществ характерно улучшение профиля ненасыщенных жирных кислот $(10,11)$ и аминокислот $(12,13)$ в мясе.

При решении проблем профилактики или борьбы с бактериальными инфекциями сельскохозяйственных животных и птицы более полную картину потенциала растительных экстрактов дает оценка их влияния на микробиом кишечника, а также на качество получаемой продукции. Ожидается, что полученные сведения будут полезны не только при разработке более эффективных и простых методов использования природных терапевтических средств против бактерий, но и для повышения продуктивности животноводства и птицеводства в целом.

В настоящее время исследования различных растительных экстрактов указывают широкие возможности такого подхода (14-16). Однако работы по изучению подобных эффектов у коры дуба относительно немногочисленны (17-19), хотя известно, что она обладает антибактериальными свойствами и антикворум-эффектами (20). Ранее мы показали, что экстракт Quercus cortex в сочетании с пробиотиком (21), ферментным препаратом (22) и в зависимости от состава веществ (23) положительно влияет на иммунитет и продуктивность бройлеров.

В настоящем сообщении мы представляем данные, характеризующие влияние экстракта Quercus cortex на продуктивные свойства, аминокислотный и жирнокислотный профили мяса, а также на структуру и численность микробиоценоза слепого кишечника у цыплят-бройлеров. Подобные исследования в доступной литературе нам не известны.

Целью работы был метагеномный анализ кишечной микробиоты цыплят-бройлеров в сопоставлении с оценкой их продуктивности и потребительских качеств мяса при добавлении в рационы разных доз экстракта Quercus cortex.

Методика. Исследования проводили на бройлерах кросса Смена 8 в условиях экспериментально-биологической клиники (виварий) (ФНЦ биологических систем и агротехнологий РАН, 2019 год). Методом аналогов из 7-суточных цыплят были сформированы четыре группы (контрольная и три опытные) по 30 гол. в каждой группе. Контрольная группа в течение всего эксперимента (35 сут) находилась на основном рационе (OP), I-III опытные группы получали дополнительно к ОР экстракт коры дуба (Quercus cortex) в 
дозировке соответственно 1, 2 и 3 мл/кг живой массы. Содержание птицы и процедуры при выполнении экспериментов соответствовали требованиям инструкций и рекомендациям российского регламента (Приказ МЗ СССР № 755 от 12.08.1977), а также «The Guide for Care and Use of Laboratory Animals (National Academy Press, Washington, D.C., 1996)». Убойные качества тушек оценивали по завершении эксперимента согласно ГОСТ 31962-2013.

Для приготовления экстракта кору дуба измельчали, приливали дистиллированную воду в соотношении $1: 1$, нагревали на водяной бане в течении 30 мин, процеживали и фильтровали (фильтры обеззоленные «белая лента», d = 70 мм, ООО «Реакон Плюс», Россия).

Микробное биоразнообразие слепого отдела кишечника птицы оценивали на 42-е сут. При выделении ДНК отобранные пробу содержимого инкубировали при $37^{\circ} \mathrm{C}$ в течение 30 мин в 300 мкл стерильного буфера для лизиса (20 мМ EDTA, 1400 мM NaCl, 100 мM Tris-HCl, pH 7,5; 50 мкл раствора лизоцима в концентрации 100 мг/мл). К смеси добавляли 10 мкл протеиназы К («Thermo Fisher Scientific, Inc.», США) в концентрации 10 мг/мл и SDS до конечной концентрации 1,0\% и инкубировали в течение 30 мин при $60{ }^{\circ} \mathrm{C}$. ДНК очищали смесью фенола и хлороформа (1:1), осаждали добавлением ацетата натрия (3 M, до $10 \%$ по объему) и трех объемов абсолютного этанола при $-20{ }^{\circ} \mathrm{C}$ в течение 4 ч. После экстракции смесью фенол:хлороформ:изоамиловый спирт (25:24:1) и хлороформ:изоамиловый спирт (24:1) ДНК в водной фазе осаждали 1 М ацетатом аммония (до $10 \%$ по объему) и 3-кратным объемом безводного этанола в течение ночи при $-20{ }^{\circ} \mathrm{C}$. Осадок ДНК отделяли центрифугированием (12000 об/мин, 10 мин), дважды промывали 80 \% этанолом, сушили и растворяли в ТЕ-буфере (1 M Tris- $\mathrm{HCl}, \mathrm{pH} 8,0-1$ мл, 0,5 М EDTA, pH 8,0 - 200 мкл, Н2О до 100 мл; «Евроген», Россия). Чистоту экстракции оценивали по отрицательному контролю выделения (100 мкл автоклавированной деионизированной воды). Чистоту полученных препаратов ДНК проверяли электрофорезом в 1,5\% агарозном геле с фотометрией (NanoDrop 8000, «Thermo Fisher Scientific, Inc.», США). Концентрацию ДНК измеряли флуориметрическим методом (прибор Qubit 2.0 с высокой чувствительностью определения dsDNA, «Life Technologies», США.

ДНК-библиотеки для секвенирования были созданы по протоколу «Illumina, Inc.» (США) с праймерами S-D-Bact-0341-b-S-17 и S-D-Bact0785-a-A-21 к вариабельному участку V3-V4 гена 16S pPHK (24). NGS-ceквенирование выполняли на платформе MiSeq («Illumina, Inc.», США) с набором реактивов MiSeq Reagent Kit V3 PE600 («Illumina, Inc.», США) в Центре коллективного пользования научным оборудованием «Персистенция микроорганизмов» (Институт клеточного и внутриклеточного симбиоза УрО РАН). Классификацию полученных операционных таксономических единиц (OTE, OTU) проводили с использованием интерактивного инструмента VAMPS и базы данных RDP (http://rdp.cme.msu.edu). Некоторые ОTЕ выравнивали с помощью алгоритма BLAST (http://blast.ncbi.nlm.nih.gov/Blast.cgi), используя базы данных нуклеотидных последовательностей nr/nt (National Center for Biotechnological Information, NCBI, https://www.ncbi.nlm.nih.gov/) и выравненных последовательностей генов рибосомальной PHK SILVA (https://www.arb-silva.de).

Исследования биохимических показателей мяса включали определение химического состава ткани, в том числе массовой доли жира по ГОСТ 23042-86 золы - по ГОСТ 15113-77; белка - методом Кьельдаля по ГОСТ 23327-78 с предварительной минерализацией проб; содержание аминного азота - формольным титрованием; массовой доли влаги - по 
ГОСТ 15113.8-77.

Для оценки биологической полноценности мяса в средней пробе и длиннейшей мышцы спины определяли содержание заменимых и незаменимых аминокислот методом капиллярного электрофореза (система Капель-105 М, «Люмэкс», Россия; ГОСТ Р 55569-2013) в соответствии с протоколом производителя. Пробоподготовка включала гомогенизацию тканей, высушивание при температуре 60-70 ${ }^{\circ} \mathrm{C}$, измельчение, кислотный или щелочной (только для триптофана) гидролиз при температуре $110{ }^{\circ} \mathrm{C}$ в течение 14-16 ч. После кислотного гидролиза пробы подвергали фильтрации (при щелочном фильтрация не требуется). Гидролизаты выпаривали в потоке теплого воздуха. Сухой остаток разбавляли в дистиллированной воде и осветляли центрифугированием. Надосадочную жидкость использовали для анализа методом капиллярного электрофореза.

Жирнокислотный состав липидов мышечной ткани определяли методом газовой хроматографии (хроматограф Кристалл Люкс 4000, ООО НПФ «Мета-хром», Россия; ГОСТ Р 55483-2013). Аналитическим стандартом служила смесь эфиров жирных кислот Supelco® 37 Component FAME Mix («Sigma-Aldrich», США).

Статистическую обработку полученных данных проводили с помощью программы Statistica 10.0 («StatSoft, Inc.», США). Результаты представлены в виде среднего арифметического значения $(M)$ и стандартной ошибки среднего $( \pm \mathrm{SEM})$. Различия считали статистически значимыми при $\mathrm{p} \leq 0,05$ (25). При биоинформатической обработке результатов секвенирования применяли комплекс программ USEARCH v8.0.1623_win32 (https://www.drive5.com/usearch/download.html). Обработка включала слияние парных ридов в операционных таксономических единицах, фильтрацию ридов по качеству и длине (минимальный размер - 300 bp), удаление химер, даблтонов и синглтонов, кластеризацию ридов в ОТЕ на уровне сходства $97 \%$ (26).

Результаты. Дополнительное включение в рацион сельскохозяйственной птицы биологических добавок непосредственно влияет на качество мяса, что в итоге может позволить получать мышечную ткань с высокой питательной и/или биологической ценностью, а при необходимости и жировую $(27,28)$. При производстве и реализации цыплят-бройлеров учитывается качество как тушек в целом, так и их частей, для которых определяют энергетическую ценность и может быть рассчитан экономический эффект от применения кормовых добавок (табл. 1).

1. Убойные качества бройлеров кросса Смена 8 при использовании растительного экстракта Quercus cortex (виварий, ФНЦ биологических систем и агротехнологий РАН, г. Оренбург, 2019 год)

\begin{tabular}{lc|c|c|c}
\hline \multicolumn{1}{c|}{ Показатель } & Контроль & I группа & II группа & III группа \\
\hline Предубойная масса, г & $2448,5 \pm 104,4$ & $2597,3 \pm 204,9^{*}$ & $2257,6 \pm 100,7^{* *}$ & $2176,5 \pm 78,5^{*}$ \\
Полупотрошенная тушка, г & $2053,0 \pm 101,9$ & $2188,7 \pm 184,9$ & $1899,2 \pm 99,5$ & $1856,5 \pm 73,3^{*}$ \\
Убойный выход полупотрошенной & & & $85,3 \pm 4,60^{*}$ \\
тушки, \% & $83,8 \pm 2,30$ & $84,3 \pm 3,10$ & $84,1 \pm 2,60$ & $85,0 \pm 0$ \\
Масса потрошенной тушки, г & $1595,5 \pm 98,8$ & $1725,3 \pm 165,3^{*}$ & $1490,0 \pm 77,3$ & $1444,0 \pm 71,1^{*}$ \\
Убойный выход потрошенной тушки, \% & $65,2 \pm 1,61$ & $67,4 \pm 1,18^{*}$ & $66,0 \pm 1,08$ & $66,4 \pm 1,15$ \\
Индекс мясных качеств & 2,39 & 2,36 & 2,27 & 2,31 \\
Мясокостный индекс & 2,10 & 2,08 & 2,23 & 2,49
\end{tabular}

П р и м е ч а н и е. Описание групп см. в разделе «Методика».

*, ** Различия с контролем статистически значимы соответственно при $\mathrm{p} \leq 0,05$ и $\mathrm{p} \leq 0,01$.

При хорошем развитии мышечной ткани выход съедобных частей тушек будет выше, как следствие, изменится индекс мясных качеств (соотношение содержания жира и общего белка) и мясокостный индекс (соот- 
ношение массы мышц и костей). Во всех экспериментальных группах индекс мясных качеств уступал показателю в контроле, но при этом в I группе он был выше, чем во II и III. Мясокостный индекс был максимальным в III опытной группе (15,7 \% был выше, чем в контрольной группе), при этом в I группе он оказался на 0,95 \% ниже, чем в контроле. В целом дополнительное включение экстракта коры дуба в рацион цыплятам-бройлерам способствовало повышению общего выхода мяса по сравнению с контрольной группой, что согласуется с результатами D. Jamroz с соавт. (29).

Максимальное количество влаги отмечали в I опытной группе (на $1,01 \%$ выше контроля). Содержание сырого жира в I группе достоверно снизилось относительно контроля (на 27,3\%, p $\leq 0,01$ ), тогда как во II оно достоверно повысилось (в 1,54 раза, $\mathrm{p} \leq 0,01)$ по сравнению с контролем. Содержание сырого протеина в образцах от бройлеров из опытных групп варьировало от 18,78 по 19,90 \% при максимальных показателях также в I опытной группе (относительно контроля и остальных опытных групп, $\mathrm{p} \leq 0,05$ ). Похожее распределение отмечали и по содержанию золы (недостоверный рост в I группе на $0,03 \%$ относительно контроля).

Один из важных критериев качества мяса цыплят-бройлеров - его биологическая ценность, которая определяется аминокислотным и жирнокислотным составом. Снижение либо резкое увеличение накопления аминокислот может указать на отрицательное воздействие введенного препарата или биологически активного вещества, что, в свою очередь, повлияет на органолептические свойства продукции, которая уже не будет соответствовать требованиям ГОСТ.

2. Содержание аминокислот (\%) в грудных мышцах цыплят-бройлеров кросса Смена 8 при использовании растительного экстракта Quercus cortex (виварий, ФНЦ биологических систем и агротехнологий РАН, г. Оренбург, 2019 год)

\begin{tabular}{|c|c|c|c|c|}
\hline Аминокислота & Контроль & I группа & II группа & III группа \\
\hline \multicolumn{5}{|c|}{ Незаменимы е аминокислоты } \\
\hline Лизин & $9,67 \pm 0,31$ & $11,30 \pm 0,28^{*}$ & $13,10 \pm 0,18^{* *}$ & $11,1 \pm 0,09^{*}$ \\
\hline Фенилаланин & $3,58 \pm 0,21$ & $4,03 \pm 0,19^{*}$ & $4,72 \pm 0,25^{*}$ & $3,83 \pm 0,17$ \\
\hline Лейцин-изолейцин & $10,7 \pm 0,21$ & $14,10 \pm 0,15^{*}$ & $15,70 \pm 0,60^{*}$ & $12,9 \pm 0,11^{*}$ \\
\hline Метионин & $2,51 \pm 0,19$ & $3,06 \pm 0,14^{*}$ & $4,44 \pm 0,21^{* *}$ & $3,48 \pm 0,15^{*}$ \\
\hline Валин & $3,46 \pm 0,15$ & $4,55 \pm 0,31^{*}$ & $5,41 \pm 0,32 *$ & $4,52 \pm 0,21^{*}$ \\
\hline Треонин & $3,97 \pm 0,24$ & $5,04 \pm 0,33^{*}$ & $5,79 \pm 0,32^{* *}$ & $4,96 \pm 0,26$ \\
\hline Сумма & $33,9 \pm 4,60$ & $42,10 \pm 3,70$ & $49,20 \pm 4,70$ & $40,80 \pm 6,20$ \\
\hline \multicolumn{5}{|c|}{3 аменимы е аминокислоты } \\
\hline Аргинин & $4,98 \pm 0,19$ & $6,83 \pm 0,24^{*}$ & $7,41 \pm 0,36^{*}$ & $7,16 \pm 0,41^{*}$ \\
\hline Тирозин & $3,87 \pm 0,40$ & $5,77 \pm 0,32 *$ & $6,17 \pm 0,31^{*}$ & $5,26 \pm 0,24 *$ \\
\hline Гисцидин & $2,45 \pm 0,31$ & $3,27 \pm 0,21$ & $3,68 \pm 0,25^{*}$ & $2,89 \pm 0,12$ \\
\hline Пролин & $2,63 \pm 0,16$ & $3,30 \pm 0,23$ & $3,75 \pm 0,32 *$ & $3,23 \pm 0,16$ \\
\hline Серин & $2,96 \pm 0,18$ & $4,10 \pm 0,21^{* *}$ & $5,24 \pm 0,24 * *$ & $4,48 \pm 0,24 *$ \\
\hline Аланин & $5,94 \pm 0,41$ & $8,35 \pm 0,36^{*}$ & $9,68 \pm 0,34 *$ & $8,11 \pm 0,51^{*}$ \\
\hline Глицин & $3,82 \pm 0,21$ & $4,97 \pm 0,29$ & $5,70 \pm 0,37 *$ & $4,82 \pm 0,32$ \\
\hline Сумма & $26,7 \pm 3,80$ & $36,60 \pm 4,50$ & $41,60 \pm 7,50$ & $35,95 \pm 4,90$ \\
\hline
\end{tabular}

Накопление ряда незаменимых кислот в грудных мышцах бройлеров в опытных группах возрастало. Так, по лизину показатели в опытных группах превышали контрольные: в I группе - на 1,63\% (p $\leq 0,05)$, во II - на $3,43 \%(\mathrm{p} \leq 0,01)$ и в III - на $1,43 \%(\mathrm{p} \leq 0,01)$ (табл. 2). Аналогичную закономерность отмечали по лейцину-изолейцину, метионину и валину - в среднем соответственно на 2,20-5,00 \% (p $\leq 0,05), 0,55-1,93 \%$ $(\mathrm{p} \leq 0,05)$ и $1,06-1,95 \%$ ( $\leq 0,05)$ относительно контроля. Содержание фенилаланина в I группе достоверно превышало контрольное на 0,45 \% $(\mathrm{p} \leq 0,05)$, во II - на $1,14 \%(\mathrm{p} \leq 0,05)$. Накопление треонина в I и II 
группах достоверно превышало контрольное соответственно на 1,07 \% $(\mathrm{p} \leq 0,05)$ и на $1,82 \%$ ( $\mathrm{p} \leq 0,01)$. Во II группе (см. табл. 2) отмечали достоверное $(\mathrm{p} \leq 0,05)$ повышение содержания всех заменимых аминокислот относительно контроля: аргинина - на 2,43\%, тирозина - на 2,30 \%, гистидина - на $1,23 \%$, пролина - на $1,12 \%$, серина - на 2,28 \%, аланина - на $3,74 \%$ и глицина - на 1,88 \%. В I и III группах по сравнению с контролем достоверно ( $\mathrm{p} \leq 0,05)$ увеличивалось количество следующих аминокислот: аргинина - соответственно на 1,85 и на $2,18 \%$, тирозина - на 1,90 и на $1,39 \%$, серина - на 1,14 и 1,52\%, аланина - на 2,41 и 2,17\% (p $\leq 0,05)$ относительно контрольной группы.

Таким образом, включение экстракта коры дуба в рацион цыплят в целом способствовало повышению суммы как незаменимых, так и заменимых аминокислот в грудных мышцах по сравнению с контролем, причем максимальный положительный эффект отмечался в группе с дозировкой экстракта коры дуба 2 мл/кг живой массы.

В бедренных мышцах цыплят-бройлеров содержание незаменимых аминокислот существенно не отличались от контроля. Так, во II опытной группе только содержание лизина и лейцина-изолейцина был достоверно ниже контрольного (соответственно на 1,84 и $2,16 \%, \mathrm{p} \leq 0,05$ ). В III группе достоверно снижалось только накопление лизина относительно контроля (на $1,66 \%, \mathrm{p} \leq 0,05$ ), в остальных случаях все изменения носили недостоверный характер. По содержанию заменимых аминокислот наблюдались схожие закономерности относительно контроля (в I группе - снижение по лизину на $1,65 \%$ при $\mathrm{p} \leq 0,05$; во II - уменьшение накопления лизина на $2,13 \%$ при $\mathrm{p} \leq 0,01$ и глицина на $0,65 \%$ при $\mathrm{p} \leq 0,05)$. Однако следует отметить, что накопление аминокислот в грудных мышцах в опытных группах не превышало предельно допустимые концентрации, оставаясь в пределах нормы.

Особой биологической ценностью обладают ненасыщенные жирные кислоты, играющие важную роль в обмене веществ у животных и человека (30). В нашем эксперименте (рис. 1) в группе, дополнительно получавшей экстракт коры дуба (1 мл/кг живой массы), достоверно повышалось накопление арахиновой кислоты (на $0,60 \%$ при $\mathrm{p} \leq 0,01$ ) относительно контроля, а дозировка 2 мл/кг живой массы увеличивала содержание стеариновой и арахиновой кислот относительно контроля (соответственно на 1,39 и $1,00 \% ; \mathrm{p} \leq 0,05)$.
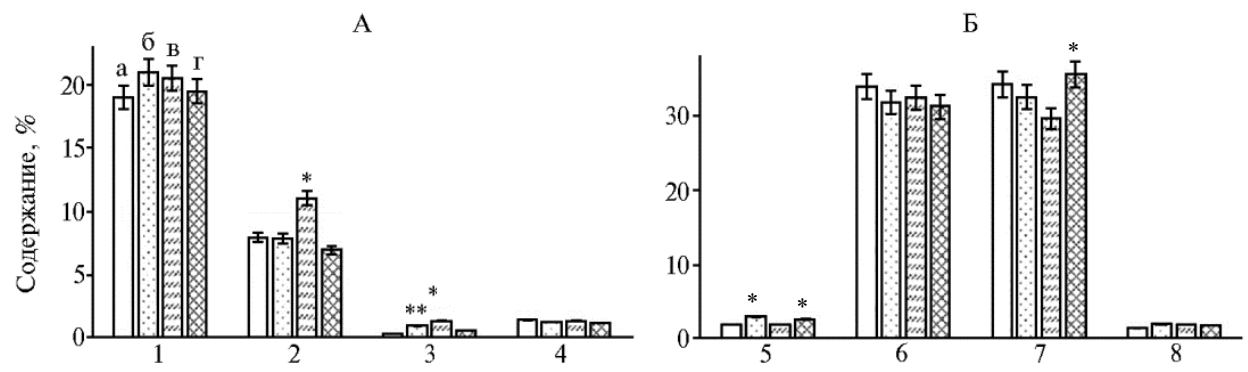

Рис. 1. Жирнокислотный состав грудных мышц у цыплят-бройлеров кросса Смена 8 при использовании растительного экстракта Quercus cortex (виварий, ФНЦ биологических систем и агротехнологий РАН, г. Оренбург, 2019 год): А - насыщенные жирные кислоты, Б - ненасыщенные жирные кислоты; а - контроль, б - I группа, в - II группа г - III группа; 1 - пальмитиновая, 2 - стеариновая, 3 - арахиновая, 4 - гондойная, 5 - линолевая, 6 - олеиновая, 7 - пальмитолеиновая, 8 - линоленовая. Звездочками (*, **) отмечены статистически значимые различия с контролем соответственно при $\mathrm{p} \leq 0,05$ и $\mathrm{p} \leq 0,01$. 
Из ненасыщенных жирных кислот в грудных мышцах цыплятбройлеров в I и III группе относительно контроля достоверно повышалось содержание пальмитолеиновой кислоты (на 1,0 и 0,7 \%; p $\leq 0,05$ ). Во II группе отмечали только достоверное снижение по линолевой кислоте (на $4,6 \%, \mathrm{p} \leq 0,05)$.

В бедренных мышцах также следует отметить ряд изменений жирнокислотного состава (рис. 2).
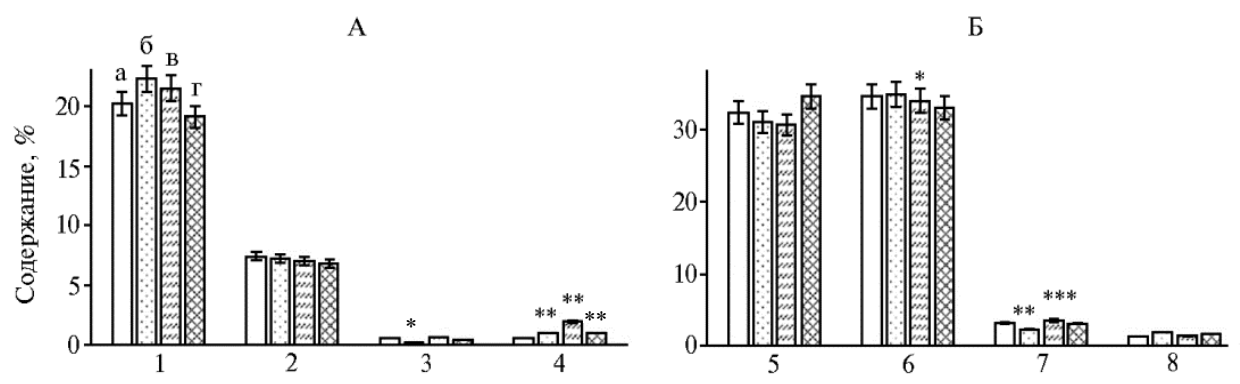

Рис. 2. Жирнокислотный состав бедренных мышц у цыплят-бройлеров кросса Смена 8 при использовании растительного экстракта Quercus cortex (виварий, ФНЦ биологических систем и агротехнологий РАН, г. Оренбург, 2019 год): А - насыщенные жирные кислоты, Б - ненасыщенные жирные кислоты; а - контроль, б - I группа, в - II группа г - III группа; 1 пальмитиновая, 2 - стеариновая, 3 - арахиновая, 4 - гондойная, 5 - линолевая, 6 олеиновая, 7 - пальмитолеиновая, 8 - линоленовая. Звездочками (*, ** и ***) отмечены статистически значимые различия с контролем соответственно при $\mathrm{p} \leq 0,05 ; \mathrm{p} \leq 0,01$ и $\mathrm{p} \leq 0,001$.

По накоплению насыщенных жирных кислот (таких как пальмитиновая и стеариновая) незначительные изменения по отношению к контролю носили недостоверный характер. Достоверно снизилось содержание арахиновой кислоты в I группе (на 0,3 \% относительно контроля, $\mathrm{p} \leq 0,05$ ). Следует также отметить достоверное повышение количества гондойновой кислоты во всех опытных группах (на 0,5-1,5\%, p $\leq 0,01)$. Схожие результаты отмечались и в исследовании S.T. Ahmed с соавт. (31) при использовании побочных продуктов обработки граната.

При изучении микробиоты слепого отдела кишечника цыплят-бройлеров с помощью метагеномного секвенирования (табл. 3) всего было классифицировано 425 OTЕ. Сравнение с базой данных SILVA показало, что эти ОТЕ принадлежали к 19 филумам, 34 классам, 71 порядку, 146 семействам, 247 родам и 297 видам.

В I группе мы выявили 277 OTЕ. Сравнение с базой данных SILVA показало, что эти ОТЕ принадлежали к 21 филуму, 38 классам, 74 порядкам, 145 семействам, 230 родам и 284 видам. Во II группе бактерии составляли 99,8 \%, не удалось классифицировать 0,2 \% микроорганизмов. При этом обнаружили 389 ОТЕ, 2 ОТЕ были удалены как контаминанты в образцах. Сравнение с базой данных SILVA показало, что оставшиеся 387 ОТЕ принадлежали к 19 филумам, 30 классам, 64 порядкам, 130 семействам, 227 родам и 310 видам. В III группе были классифицированы 406 ОТЕ, которые относятся к 19 филумам, 34 классам, 70 порядкам, 142 семействам, 240 родам и 294 видам.

Полученные результаты показали, что с увеличением дозы экстракта коры дуба в рационе численность микроорганизмов филума Bacteroidetes в опытных группах сначала снижалась (I группа), а затем эти микроорганизмы не выявлялись (II и III группы) (см. табл. 3). В I и III группах доминировали члены филума Bacteroidetes, представленные Rikenellaceae. Отметим, что в других исследованиях $(32,33)$ отмечен противоположный эффект 
по Ruminococcaceae и Lachnospiraceae. В I и III группах наблюдалось снижение представительства класса Clostridia. Ранее проведенные исследования также указывали на положительное влияние танинсодержащих веществ, которые препятствовали развитию микроорганизмов класса Clostridia $(34,35)$.

3. Таксономический состав (\%) микробиома в слепом отделе кишечника у цыплят-бройлеров кросса Смена 8 при использовании растительного экстракта Quercus cortex ( $M \pm \mathrm{SEM}$, виварий, ФНЦ биологических систем и агротехнологий РАН, г. Оренбург, 2019 год)

\begin{tabular}{|c|c|c|}
\hline Филум & Класс & Семейство \\
\hline & \multicolumn{2}{|c|}{ Контроль $(n=5)$} \\
\hline Bacteroidetes $(16,7 \pm 0,75)$ & Bacteroidia $(16,7 \pm 0,75)$ & $\begin{array}{l}\text { Rikenellaceae }(14,6 \pm 0,61) \\
\text { Bacteroidaceae }(2,1 \pm 0,08)\end{array}$ \\
\hline Firmicutes $(73,8 \pm 2,68)$ & $\begin{array}{l}\text { Bacilli }(2,68 \pm 0,13) \\
\text { Clostridia }(71,0 \pm 2,5)\end{array}$ & $\begin{array}{l}\text { Lactobacillaceae }(2,67 \pm 0,12) \\
\text { Ruminococcaceae }(11,1 \pm 0,47) \\
\text { Clostridiaceae }(20,8 \pm 0,84)\end{array}$ \\
\hline
\end{tabular}

$\begin{array}{lll} & & \\ & & (3,1 \pm 0,23) \\ & \text { Lachnospiraceae }(3,88 \pm 0,14) & \text { Blautia }(2,19 \pm 0,05) \\ \text { Proteobacteria } & \text { Другие }(35.2 \pm 0,11) & -\end{array}$

$(3,22 \pm 0,13)$

I г р у п п а $(n=5)$

Bacteroidetes $\left(66,2 \pm 3,20^{*}\right)$ Bacteroidia $\left(66,2 \pm 3,20^{*}\right) \quad$ Rikenellaceae $\left(56,2 \pm 2,44^{*}\right)$

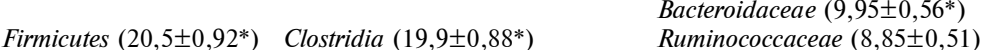

Clostridiaceae $\left(2,85 \pm 0,12^{*}\right) \quad$ Faecalibacterium

$(2,85 \pm 0,12)$

Lachnospiraceae $(2,19 \pm 0,16)$

Actinobacteria $(2,1 \pm 0,14)$ Actinobacteria $(2,1 \pm 0,14)$

Micrococcaceae $(2,1 \pm 0,14) \quad$ Rothia $(2,1 \pm 0,14)$

Proteobacteria

Gammaproteobacteria $(2,59 \pm 0,36)$

$(2,59 \pm 0,36)$

II г р упп а $(n=5)$

Firmicutes $\left(93,7 \pm 3,78^{*}\right) \quad$ Clostridia $(75,1 \pm 2,69)$

Ruminococcaceae $\left(24,5 \pm 0,87^{*}\right)$ Subdoligranulum

$(2,64 \pm 0,09)$

Ruminococcus

$(8,24 \pm 0,35)$

Clostridiaceae $(22,7 \pm 0,94)$

Faecalibacterium

$\left(13,4 \pm 0,53^{*}\right)$

Clostridium $(7,17 \pm 0,28)$

Butyricicoccus

$(2,17 \pm 0,10)$

Lachnospiraceae $\left(24,4 \pm 0,76^{*}\right) \quad$ Blautia $(3,77 \pm 0,14)$

Coprococcus

$(2,56 \pm 0,21)$

Fusicatenibacter

$(7,65 \pm 0,36)$

Bacilli $\left(18,6 \pm 0,77^{*}\right)$

Lactobacillaceae $\left(17,7 \pm 0,72^{*}\right)$

actobacillus

$\left(17,7 \pm 0,72^{*}\right)$

III г рупп а $(n=5)$

Proteobacteria $(2,09 \pm 0,24)$ Gammaproteobacteria $(2,01 \pm 0,24)$

Firmicutes $(49,9 \pm 2,47)^{*}$ Clostridia $(46,8 \pm 2,41)$

Ruminococcaceae $(18,6 \pm 0,83)$

Subdoligranulum

$(4,59 \pm 0,17)$

Ruminococcus

(2,28土0,31)

Clostridiaceae $(20,4 \pm 0,98)$

Clostridium

$\left(2,39 \pm 0,21^{*}\right)$

Faecalibacterium

$\left(17 \pm 0,72^{*}\right)$

Bacilli $(2,2 \pm 0,27)$

Lachnospiraceae $(2,85 \pm 0,18)$

Lactobacillaceae $(2,2 \pm 0,27)$

Lactobacillus

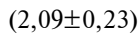

Rikenellaceae $(30,7 \pm 1,12) \quad$ Alistipes $(30,7 \pm 1,12)$

Bacteroidetes $\left(35,2 \pm 1,21^{*}\right)$ Bacteroidia $\left(35,1 \pm 1,21^{*}\right)$

Bacteroidaceae $(4,36 \pm 0,08) \quad$ Bacteroides $(4,36 \pm 0,08)$

П р и м еч а н и е. Описание групп см. в разделе «Методика». Прочерки означают, что отмеченные таксоны не были классифицированы. Микроорганизмы, отнесенные к другим неидентифицированным таксонам, не учитывали.

* Различия с контролем статистически значимы при $\mathrm{p} \leq 0,05$.

Bo II группе преобладал филум Firmicutes, представленный классами Clostridia и Bacilli, однако отсутствовал филум Bacteroidetes. Сходные эф- 
фекты наблюдались при дополнении рациона бройлеров экстрактом винограда (36). Можно сделать вывод, что дополнительное включение в рацион цыплят-бройлеров Quercus cortex непосредственно влияет на состав микрофлоры в слепом отделе кишечника (представленность таксонов Firmicutes, Bacteroidetes, Bacilli, Clostridia), что может изменять обменные процессы в организме, в частности резорбцию энергии или деградацию белков и полисахаридов.

Сообщалось, что увеличение массы бройлеров коррелировало с изменением структуры микробиоты кишечника, особенно с численностью Bacteroidetes и Firmicutes (37). При увеличении показателей роста наблюдалось резкое увеличение количества представителей Bacteroidetes и снижение доли Firmicutes. Это связано с тем, что бактерии филума Bacteroidetes в основном способны стимулировать пищеварение в кишечнике, поскольку они играют фундаментальную роль в гидролизе сложных молекул до более простых (38). Также немаловажно, что бактерии рода Alistipes (семейства Rikenellaceae) - это резистентные к желчи и необходимые для кишечника бактерии, которые способны продуцировать фибринолизин, переваривать желатин и ферментировать углеводы с образованием уксусной кислоты (39). Род Odoribacter (семейство Porphyromonadaceae) может ферментировать углеводы с образованием короткоцепочечных жирных кислот, что важно для роста как микроорганизмов, так и эпителиальных клеток макроорганизма-хозяина (40). Следовательно, улучшение ростовых показателей бройлеров может быть связано с увеличением относительной доли представителей филума Bacteroidetes в микробиоте слепой кишки в группе. Отметим также, что бактерии филума Firmicutes, в свою очередь, важны для переваривания корма (41).

Полученные нами результаты таксономического анализа на основе секвенирования последовательности гена $16 \mathrm{~S}$ рРНК согласуются с данными ряда исследований. Так, высокопроизводительное секвенирование показало, что в слепом отделе кишечника у цыплят-бройлеров преобладают филумы Firmicutes (42) и Bacteroidetes (43). Однако сообщается и о том, что возможно преобладание филума Proteobacteria (44). Такая вариабельность в доминировании представителей различных филумов может быть связана как с особенностями методологии секвенирования (в разных исследованиях могут использоваться неодинаковые праймеры, которые, несмотря на универсальность, более специфичны к тем или иным последовательностям гена $16 \mathrm{~S}$ рРНК у микроорганизмов), так и с внешними факторами (изменение климатических условий, рацион, возраст и порода исследуемой сельскохозяйственной птицы). Стоит отметить, что в таксон Proteobacteria входят представители условно-патогенной группы кишечных бактерий. В нашем исследовании происходило снижение числа представителей Proteobacteria: в I опытной группе - на 19,56 \%, в III - на 35,09 \% по сравнению с контрольной группой, и хотя эти различия не были статистически достоверными, выявленная тенденция может представлять значительный интерес.

Предполагают, что фенольные соединения, содержащиеся в растительных экстракта, в том числе и экстракте коры дуба, могут повреждать клеточную мембрану бактерий, взаимодействуя с мембранными белками, или вовлекаться во взаимодействие с клеточными ферментами, что прямо или косвенно вызывает метаболическую дисфункцию и гибель бактерий (45). Фенольные соединения также способны ингибировать рецепторы сигнала Quorum Sensing и снижать секрецию токсинов (46). При этом контроль 
патогенной микрофлоры кишечника с помощью растительных экстрактов, по мнению ряда авторов, может отличаться от прямого действия антибактериальных препаратов и включать другие механизмы. Так, было показано, что включение в рацион экстракта, содержащего капсаицин, карвакрол и коричный альдегид, приводит к значительному увеличению количества Lactobacillus spp. (47). В эксперименте на крысах это было связано со стимуляцией роста Lactobacillus и продукцией молочной кислоты в присутствии карвакрола (48).

Обсуждая результаты по увеличению содержания треонина, стоит отметить, что, как сообщалось (49), эндогенные потери некоторых аминокислот (при оценке их количества в экскрементах) увеличивались под влиянием дубильной кислоты, которая обнаруживается в растительных экстрактах. Это касалось метионина, гистидина и лизина, тогда как у треонина, цистеина и валина экскреция была наименьшей. Также предполагается, что танины могут влиять на реабсорбцию аминокислот из просвета кишечника. Есть сообщения о неблагоприятных воздействиях in vitro и in vivo чистых танинов и растительных экстрактов на кишечную абсорбцию и транспорт аминокислот, таких как пролин, метионин, аланин и фениаланин (50).

Выявленное нами повышение содержания полиненасыщенных жирных кислот согласуется с результатами, полученными J. Koreleski c coaвт. (51). Они показали, что использование экстракта шалфея повышает содержание арахиноновой кислоты в грудных мышцах цыплят. Кроме того, эти же авторы описали различные эффекты экстрактов шалфея и рудбекии. Так, доза 560 мг, добавленная в корм для домашней птицы, способствовала изменению профиля жирных кислот. Добавление экстракта шалфея в рацион уменьшило накопление полиненасыщенных жирных кислот в грудных мышцах по сравнению с контролем.

Известно о положительном влиянии некоторых лекарственных растений на продуктивные и экономические показатели при выращивании сельскохозяйственной птицы, в частности на липидный обмен в печени и антиоксидантный статус организма (52). Ранее сообщалось (53), что в экспериментальных группах, которые получали добавки, содержащие полифенолы, у птицы увеличивалось количества белка в грудных мышцах. Метаболиты фенольных соединений (дубильные и другие вещества), в том числе содержащиеся в экстракте Quercus cortex, обладают антиоксидантными свойствами (54), что может повлиять на профиль жирных кислот в мышечной ткани. Низкое содержание липидов в мясе птицы и относительно высокое - полиненасыщенных жирных кислот рассматривают как одно из основных полезных свойств этого ценного пищевого продукта (55).

Следует, однако, отметить, что некоторые биологически активные вещества, содержащиеся в растительных экстрактах и выполняющие защитные функции в растительных тканях, могут неоднозначно влиять на организм животных (56), в частности на такие существенные процессы, как обмен белков и жиров. Важно помнить, что в составе рационов микроэлементы взаимодействуют друг с другом (57). Известно свойство танинов связываться с ферментами, причем различия в химической структуре этих полифенолов могут влиять на такие взаимодействия $(58,59)$ и, как следствие, на метаболические процессы, которые к тому же изменяются в разные периоды выращивания птицы. При определенной дозе танины оказывают положительное влияние на продуктивность $(60,61)$.

Итак, результаты проведенных нами исследований показали, что при использовании экстракта коры дуба как кормовой добавки в мясе 
бройлеров повышается содержание аминокислот и ненасыщенных жирных кислот по сравнению с контрольной группой, не получавшей такую добавку. При дозировке 1 мл/кг живой массы экстракт коры дуба снижает содержание жира в тушке. Экстракт также положительно влияет на микробиоту слепого отдела кишечника бройлеров, увеличивая численность микроорганизмов из филумов Bacteroidetes и Firmicutes, которые необходимы для нормального переваривания пищи в кишечнике птицы. Следовательно, применение экстракта коры дуба в кормлении цыплят-бройлеров в дозировке 1-3 мл/кг живой массы интенсифицирует процессы пищеварения в кишечнике и способствует повышению содержания аминокислот, ненасыщенных жирных кислот в мясе тушки, что улучшает потребительские свойства продукта.

\author{
1 ФГБНУ Федеральный научный центр \\ животноводства - ВИЖ им. академика Л.К. Эрнста, \\ 142132 Россия, Московская обл., г.о. Подольск, пос. Дубровицы, 60, \\ e-mail: vugarbagirov@mail.ru, asu2004@bk.ru; \\ 2ФГБНУ Федеральный научный центр биологических \\ систем и агротехнологий $Р A H$, \\ 460000 Россия, г. Оренбург, ул. 9 Января, 29, \\ e-mail: gduskaev@mail.ru $₫$, kwan111@yandex.ru, shahm2005@rambler.ru, \\ vasilena56@mail.ru, gavrish.irina.ogu@gmail.com
}

Поступила в редакцию 11 января 2020 года

\title{
METAGENOMIC ANALYSIS OF INTESTINAL MICROBIOME AND BIOCHEMICAL COMPOSITION OF BROILER MEAT UPON USE OF Quercus cortex EXTRACT DIETARY ADDITIVE
}

\author{
V.A. Bagirov', A.S. Ushakov', G.K. Duskaev², O.V. Kvan', Sh.G. Rakhmatullin', \\ E.V. Yausheva ${ }^{2}$, I.A. Vershinina ${ }^{2}$
}

\begin{abstract}
${ }^{1}$ Ernst Federal Science Center for Animal Husbandry, 60, pos. Dubrovitsy, Podolsk District, Moscow Province, 142132 Russia, e-mail vugarbagirov@mail.ru, asu2004@bk.ru;

${ }^{2}$ Federal Research Centre of Biological Systems and Agrotechnologies RAS, 29, ul. 9 Yanvarya, Orenburg, 460000 Russia, e-mail gduskaev@mail.ru ( $₫$ corresponding author), kwan111@yandex.ru, shahm2005@rambler.ru, vasilena56@mail.ru, gavrish.irina.ogu@gmail.com
\end{abstract}

ORCID:

Bagirov V.A. orcid.org/0000-0001-5398-8815

Ushakov A.S. orcid.org/0000-0001-5253-6083

Duskaev G.K. orcid.org/0000-0002-9015-8367

Rakhmatullin Sh.G. orcid.org/0000-0003-0143-9499

Yausheva E.V. orcid.org/0000-0002-1589-2211

Kvan O.V. orcid.org/0000-0003-0561-7002

Vershinina I.A. orcid.org/0000-0002-9377-7673

The authors declare no conflict of interests

Acknowledgements:

Supported financially by Russian Science Foundation (project No. 16-16-10048 P)

Received January 11, 2020

doi: 10.15389 /agrobiology.2020.4.682eng

\section{Abstract}

Today, the use of antibiotics in veterinary medicine, as well as growth stimulants in animal husbandry, is considered the main reason for the development of bacterial resistance to antibiotics. Plant-based water extracts can provide simple new approaches to control pathogenic bacteria. Active search for natural alternative sources of antimicrobials, including wild plants, are almost unlimited source of phytochemicals. Plant-based water extracts can also provide simple new approaches to controlling pathogenic bacteria. Some authors suggest that an increase in broiler growth after adding active components of plants may be associated with an improvement in the microbial composition of the intestine and metabolic function. Other plant substances can improve the profile of unsaturated fatty acids and amino acids in meat. Thus, in order to get a more complete picture of the potential use of plant extracts for the prevention or control of bacterial infections, the most significant studies concern the evaluation of the activity of plant extracts in relation to the quality of products and the intestinal microbiome of farm animals and poultry. The aim of our experiment was to study the effect of Quercus cortex extract on biochemical composition of broiler chicken meat and intestinal microbiomes. The studies were carried out with Smena 8 broiler chickens (the Common Use Center for the scientific equipment of the BST RAS, in 2019). In the experiment, 120 broiler chickens aged 7-day were 
randomly assigned to 4 groups ( $n=30$ each, in 4 repetitions). The control broilers were fed the Basic Diet (BD); group I - BD + Quercus cortex extract 1 (1 ml/kg lw); group II - BD + Quercus cortex extract $2(2 \mathrm{ml} / \mathrm{kg} \mathrm{lw})$; group III - BD + Quercus cortex extract $3(3 \mathrm{ml} / \mathrm{kg} \mathrm{lw})$. Analysis of chemical composition of broiler chicken meat showed that the additional inclusion of oak bark extract at a dose of $1 \mathrm{ml} / \mathrm{kg}$ of live weight in the diet of the studied poultry helps to improve the quality of meat due to a $27.3 \%$ ( $\mathrm{p} \leq 0.01)$ increase in moisture, crude protein and ash, while reducing the level of crude fat. The dietary oak bark extract contributed to an increase in the amount of essential amino acids, for lysine by $1.63-3.43 \%$ ( $\leq \leq 0,01$, for leucine-isoleucine by $2.20-5.00 \%$ ( $\mathrm{p} \leq 0.05$ ), for methionine by $0.55-1.93 \%(\mathrm{p} \leq 0.05)$, for valine by $1.06-1.95 \%(\mathrm{p} \leq 0.05)$, for phenylalanine (group I and II) by $0.45 \%$ and $1.14 \%$, respectively ( $\mathrm{p} \leq 0.05)$, for threonine (group I and II) by $1.07 \%(\mathrm{p} \leq 0.05)$ and $1.82 \%$ ( $\mathrm{p} \leq 0.01)$. Levels of non-essential amino acids in the pectoral muscles of broiler chickens compared to control also changed, with the maximum observed for a dosage of $2 \mathrm{ml} / \mathrm{kg}$ lw of oak bark extract. The content of unsaturated fatty acids in groups I and III increased compared to the control (for palmitoleic acid by 1.00 and $0.70 \%$, respectively, $\mathrm{p} \leq 0.05$ ). Different dosages of dietary Quercus cortex extract have a significant effect on microbiota of the blind intestine. Changes affect phyla Firmicutes and Bacteroidetes, involved in metabolic energy resorption and degradation of proteins and polysaccharides. The abundance of phylum Bacteroidetes increased 3.96-fold and 2.10-fold in groups I and III compared to the control $(\mathrm{p} \leq 0.05)$, while in group II these bacteria were not found. The number of members of Firmicutes phylum decreased 3.60-fold and 1.47-fold (in groups I and III vs. the control, $\mathrm{p} \leq 0.05$ ) while increased 1.26 times in group II vs. the control, $\mathrm{p} \leq 0.05$ ) Thus, broilers fed 1-3 ml/kg dietary Quercus cortex extract were superior to other birds in terms of amino acid and unsaturated fatty acid levels in carcass due intensification of digestion in intestine, which improves consumer quality of meat.

Keywords: microbiome, broiler chickens, oak bark extract, fatty acids, amino acids.

\section{R E F EREN CES}

1. Abiala M., Olayiwola J., Babatunde O., Aiyelaagbe O., Akinyemi S. Evaluation of therapeutic potentials of plant extracts against poultry bacteria threatening public health. BMC complementary and alternative medicine, 2016, 16: 417 (doi: 10.1186/s12906-016-1399-z).

2. Ali S.M., Siddiqui R., Khan N.A. Antimicrobial discovery from natural and unusual sources. Journal of Pharmacy and Pharmacology, 2018, 70(10): 1287-1300 (doi: 10.1111/jphp.12976).

3. Al-Tohamy R., Ali S.S., Saad-Allah K., Fareed M., Ali A., El-Badry A., El-Zawawyb N. A., Wua J., Suna J., Maof G., Rupani P.F. Phytochemical analysis and assessment of antioxidant and antimicrobial activities of some medicinal plant species from Egyptian flora. Journal of Applied Biomedicine, 2018, 16(4): 289-300 (doi: 10.1016/j.jab.2018.08.001).

4. Santos S.A., Martins C., Pereira C., Silvestre A.J., Rocha S.M. Current challenges and perspectives for the use of aqueous plant extracts in the management of bacterial infections: the case-study of Salmonella enterica Serovars. Int. J. Mol. Sci., 2019, 20(4): 940 (doi: 10.3390/ijms20040940).

5. Suurbaar J., Mosobil R., Donkor A.M. Antibacterial and antifungal activities and phytochemical profile of leaf extract from different extractants of Ricinus communis against selected pathogens. BMC Res. Notes, 2017, 10(1): 660 (doi: 10.1186/s13104-017-3001-2).

6. Zhu N., Wang J., Yu L., Zhang Q., Chen K., Liu B. Modulation of growth performance and intestinal microbiota in chickens fed plant extracts or virginiamycin. Front. Microbiol., 2019, 10: 1333 (doi: 10.3389/fmicb.2019.01333).

7. Diaz Carrasco J.M., Redondo L.M., Redondo E.A., Dominguez J.E., Chacana A.P., Fernandez Miyakawa M.E. Use of plant extracts as an effective manner to control Clostridium perfringens induced necrotic enteritis in poultry. BioMed Research International, 2016, 2016: 3278359 (doi: $10.1155 / 2016 / 3278359)$.

8. Ezzat H.N., Abood S.S., Jawad H.S. A review on the effects of neem (Azadirachta indica) as feed additive in poultry production. Jornal of Entomology and Zoology Studies, 2018, 6(1): 1331-1333.

9. Oyeagu C.E., Mlambo V., Muchenje V., Marume U. Effect of dietary supplementation of aspergillus xylanase on broiler chickens performance. Iranian Journal o Applied Animal Science, 2019, 9(4): 693-708.

10. Kishawy A.T., Amer S.A., El-Hack M.E., Saadeldin I.M., Swelum A.A. The impact of dietary linseed oil and pomegranate peel extract on broiler growth, carcass traits, serum lipid profile, and meat fatty acid, phenol, and flavonoid contents. Asian-Australasian Journal of Animal Sciences, 2019, 32(8): 1161-1171 (doi: 10.5713/ajas.18.0522).

11. Mpofu D., Marume U., Mlambo V., Hugo A. The effects of Lippia javanica dietary inclusion on growth performance, carcass characteristics and fatty acid profiles of broiler chickens. Animal Nutrition, 2016, 2(3): 160-167 (doi: 10.1016/j.aninu.2016.05.003).

12. Díaz Carrasco J.M., Redondo E.A., Pin Viso N.D., Redondo L.M., Farber M.D., Fernández Miyakawa M.E. Tannins and bacitracin differentially modulate gut microbiota of broiler chickens. 
BioMed Research International, 2018, 2018: 1879168 (doi: 10.1155/2018/1879168).

13. Tosi G., Massi P., Antongiovanni M., Buccioni A., Minieri S., Marenchino L., Mele M. Efficacy test of a hydrolysable tannin extract against necrotic enteritis in challenged broiler chickens. Italian Journal of Animal Science, 2013, 12: e62 (doi: 10.4081/ijas.2013.e62).

14. Shokraneh M., Ghalamkari G., Toghyani M., Landy N. Influence of drinking water containing Aloe vera (Aloe barbadensis Miller) gel on growth performance, intestinal microflora, and humoral immune responses of broilers. Veterinary World, 2016, 9(11): 1197-1203 (doi: 10.14202/vetworld.2016.1197-1203).

15. Starčević K., Krstulović L., Brozić D., Maurić M., Stojević Z., Mikulec Ž., Mikulec M., Bajic M., Mašek T. Production performance, meat composition and oxidative susceptibility in broiler chicken fed with different phenolic compounds. J. Sci. Food Agric., 2015, 95(6): 1172-1178 (doi: 10.1002/jsfa.6805).

16. Bourre J.M. Where to find omega-3 fatty acids and how feeding animals with diet enriched in omega-3 fatty acids to increase nutritional value of derived products for human: what is actually useful. J. Nutr. Health Aging, 2005, 9(4): 232-242.

17. Karimi A., Moradi M.T. Total phenolic compounds and in vitro antioxidant potential of crude methanol extract and the correspond fractions of Quercus brantii L. acorn. Journal of HerbMed Pharmacology, 2015, 4(1): 35-39.

18. Gessner D.K., Ringseis R., Eder K. Potential of plant polyphenols to combat oxidative stress and inflammatory processes in farm animals. J. Anim. Physiol. Anim. Nutr., 2017, 101(4): 605-628 (doi: 10.1111/jpn.12579).

19. Mondal S., Haldar S., Saha P., Ghosh T.K. Metabolism and tissue distribution of trace elements in broiler chickens' fed diets containing deficient and plethoric levels of copper, manganese, and zinc. Biol. Trace Elem. Res., 2010, 137(2): 190-205 (doi: 10.1007/s12011-009-8570-z).

20. Schiavone A., Guo K., Tassone S., Gasco L., Hernandez E., Denti R., Zoccarato I. Effects of a natural extract of chestnut wood on digestibility, performance traits, and nitrogen balance of broiler chicks. Poultry Science, 2008, 87(3): 521-527 (doi: 10.3382/ps.2007-00113).

21. Tonsor G.T., Wolf C.A. US farm animal welfare: an economic perspective. Animals, 2019, 9(6): 367 (doi: 10.3390/ani9060367).

22. Wilson R.T. Domestic livestock in African cities: production, problems and prospects. Open Urban Studies and Demography Journal, 2018, 4(1): 1-14 (doi: 10.2174/2352631901804010001).

23. Nkukwana T.T. Global poultry production: current impact and future outlook on the South African poultry industry. South African Journal of Animal Science, 2018, 48(5): 869-884 (doi: 10.4314/sajas.v48i5.7).

24. Mancabelli L., Ferrario C., Milani C., Mangifesta M., Turroni F., Duranti S., Ventura M. Insights into the biodiversity of the gut microbiota of broiler chickens. Environmental Microbiology, 2016, 18(12): 4727-4738 (doi: 10.1111/1462-2920.13363).

25. Duskaev G.K., Rakhmatullin S.G., Kazachkova N.M., Sheida Y.V. Mikolaychik I.N., Morozova L.A., Galiev B.H. Effect of the combined action of Quercus cortex extract and probiotic substances on the immunity and productivity of broiler chickens. Veterinary World, 2018, 11(10): 1416-1422 (doi: 10.14202/vetworld.2018.1416-1422).

26. Meehan C.J., Beiko R.G. A phylogenomic view of ecological specialization in the Lachnospiraceae, a family of digestive tract-associated bacteria. Genome Biology and Evolution, 2014, 6: $703-$ 713 (doi: 10.1093/gbe/evu050).

27. Bagirov V.A., Duskaev G.K., Kazachkova N.M., Rakhmatullin S.G., Yausheva E.V., Kosyan D.B., Makaev S.A., Dusaeva K.B. Addition of Quercus cortex extract to broiler diet changes slaughter indicators and biochemical composition of muscle tissue. Agricultural Biology, 2018, 53(4): 799-810 (doi: 10.15389/agrobiology.2018.4.799eng).

28. Wang J., Wang X., Li J., Chen Y., Yang W., Zhang L. Effects of dietary coconut oil as a mediumchain fatty acid source on performance, carcass composition and serum lipids in male broilers. Asian-Australasian Journal of Animal Sciences, 2015, 28(2): 223-230 (doi: 10.5713/ajas.14.0328).

29. Jamroz D., Orda J., Kamel C., Wiliczkiewicz A., Wertelecki T., Skorupinska J. The influence of phytogenic extracts on performance, nutrient digestibility, carcass characteristics, and gut microbial status in broiler chickens. Journal of Animal and Feed Sciences, 2003, 12(3): 583-596 (doi: 10.22358/jafs/67752/2003).

30. Tvrzicka E., Kremmyda L.S., Stankova B., Zak, A. Fatty acids as biocompounds: their role in human metabolism, health and disease-a review. Part 1: classification, dietary sources and biological functions. Biomedical Papers of the Medical Faculty of Palacky University in Olomouc, 2011, 155(2): 117-130 (doi: 10.5507/bp.2011.038).

31. Ahmed S.T., Islam M.M., Bostami A.R., Mun H.S., Kim Y.J., Yang C.J. Meat composition, fatty acid profile and oxidative stability of meat from broilers supplemented with pomegranate (Punica granatum L.) by-products. Food Chemistry, 2015, 188: 481-488 (doi: 10.1016/j.foodchem.2015.04.140).

32. Ran C., Hu J., Liu W., Liu Z., He S., Dan B.C., Diem N.N., Ooi E.L., Zhou Z. Thymol and carvacrol affect hybrid tilapia through the combination of direct stimulation and an intestinal 
microbiota-mediated effect: insights from a germ-free zebrafish model. The Journal of Nutrition, 2016, 146(5): 1132-1140 (doi: 10.3945/jn.115.229377).

33. Chen W.L., Tang S.G., Jahromi M.F., Candyrine S.C., Idrus Z., Abdullah N., Liang J.B. Metagenomics analysis reveals significant modulation of cecal microbiota of broilers fed palm kernel expeller diets. Poultry Science, 2019, 98(1): 56-68 (doi: 10.3382/ps/pey366).

34. Xiao Y., Xiang Y., Zhou W., Chen J., Li K., Yang, H. Microbial community mapping in intestinal tract of broiler chicken. Poultry Science, 2017, 96(5): 1387-1393 (doi: 10.3382/ps/pew372).

35. Singh K., Shah T., Deshpande S., Jakhesara S., Koringa P., Rank D. High through put 16S rRNA gene-based pyrosequencing analysis of the fecal microbiota of high FCR and low FCR broiler growers. Molecular Biology Reports, 2012, 39: 10595-10602 (doi: 10.1007/s11033-0121947-7).

36. Viveros A., Chamorro S., Pizarro M., Arija I., Centeno C., Brenes A. Effects of dietary polyphenol-rich grape products on intestinal microflora and gut morphology in broiler chicks. Poultry Science, 2011; 90(3): 566-578 (doi: 10.3382/ps.2010-00889).

37. Molnar A.K., Podmaniczky B., Kurti P., Tenk I., Glavits R., Virag G., Szabo Z. Effect of different concentrations of Bacillus subtilis on growth performance, carcase quality, gut microflora and immune response of broiler chickens. British Poultry Science, 2011, 52: 658-665 (doi: 10.1080/00071668.2011.636029).

38. Wexler H.M. Bacteroides: the good, the bad, and the Nitty-Gritty. Clinical Microbiology Reviews, 2007, 20: 593-621 (doi: 10.1128/CMR.00008-07).

39. Klindworth A., Pruesse E., Schweer T., Peplies J., Quast C., Horn M., Glцckner F. Evaluation of general 16S ribosomal RNA gene PCR primers for classical and next-generation sequencingbased diversity studies. Nucleic Acids Research, 2013, 41(1): 1-11 (doi:10.1093/nar/gks808).

40. Fisinin V.I., Ushakov A.S., Duskaev G.K., Kazachkova N.M., Nurzhanov B.S., Rakhmatullin S.G., Levakhin G.I. Mixtures of biologically active substances of oak bark extracts change immunological and productive indicators of broilers. Agricultural Biology [Sel'skokhozyaistvennaya Biologiya], 2018, 53(2): 385-392 (doi: 10.15389/agrobiology.2018.2.385eng).

41. Wagle B.R., Upadhyay A., Arsi K., Shrestha S., Venkitanarayanan K., Donoghue A.M., Donoghue D.J. Application of $\beta$-resorcylic acid as potential antimicrobial feed additive to reduce Campylobacter colonization in broiler chickens. Frontiers in Microbiology, 2017, 8: 599 (doi: 10.3389/fmicb.2017.00599).

42. Olnood C.G., Beski S.S., Choct M., Iji P.A. Novel probiotics: their effects on growth performance, gut development, microbial community and activity of broiler chickens. Animal Nutrition, 2015, 1(3): 184-191 (doi: 10.1016/j.aninu.2015.07.003).

43. Hartmann M., Berditsch M., Hawecker J., Ardakani M.F., Gerthsen D., Ulrich A.S. Damage of the bacterial cell envelope by antimicrobial peptides gramicidin S and PGLa as revealed by transmission and scanning electron microscopy. Antimicrobial Agents and Chemotherapy, 2010, 54: 3132-3142 (doi: 10.1128/AAC.00124-10).

44. Li Y., Xu Q., Huang Z., Lv L., Liu X., Yin C., Yuan J. Effect of Bacillus subtilis CGMCC 1.1086 on the growth performance and intestinal microbiota of broilers. Journal of Applied Microbiology, 2016, 120(1): 195-204 (doi: 10.1111/jam.12972).

45. Deryabin D., Tolmacheva A. Antibacterial and anti-quorum sensing molecular composition derived from Quercus cortex (Oak bark) extract. Molecules, 2015, 20(9): 17093-17108 (doi: 10.3390/molecules200917093).

46. Cushnie T.P.T., Lamb A.J. Recent advances in understanding the antibacterial properties of flavonoids. International Journal of Antimicrobial Agents, 2011, 38(2): 99-107 (doi: 10.1016/j.ijantimicag.2011.02.014).

47. Manzanilla E.G., Perez J.F., Martin M., Kamel C., Baucells F., Gasa J. Effect of plant extracts and formic acid on the intestinal equilibrium of early-weaned pigs. Journal of Animal Science, 2004, 82(11): 3210-3218 (doi: 10.2527/2004.82113210x).

48. Wei H., Chen G., Wang R., Peng, J. Oregano essential oil decreased susceptibility to oxidative stress-induced dysfunction of intestinal epithelial barrier in rats. Journal of Functional Foods, 2015, 18: 1191-1199 (doi: 10.1016/j.jff.2015.02.035).

49. Mansoori B., Acamovic T. The effect of tannic acid on the excretion of endogenous methionine, histidine and lysine with broilers. Animal Feed Science and Technology, 2007, 134(3-4): 198-210 (doi: 10.1016/j.anifeedsci.2006.07.00).

50. Kreydiyyeh S.I. Inhibitors in tea of intestinal absorption of phenylalanine in rats. Comparative Biochemistry and Physiology Part C: Pharmacology, Toxicology and Endocrinology, 1996, 113(1): 67-71 (doi: 10.1016/0742-8413(95)02034-9).

51. Koreleski J., Swiatkiewicz S. Dietary supplementation with plant extracts, xantophylls and synthetic antioxidants: effect on fatty acid profile and oxidative stability of frozen stored chicken breast meat. Journal of Animal and Feed Sciences, 2007, 16(3): 463-471 (doi: 10.22358/jafs/66802/2007).

52. Wang Y., Dong Z., Song D., Zhou H., Wang W., Miao H., Li. A. Effects of microencapsulated probiotics and prebiotics on growth performance, antioxidative abilities, immune functions, and caecal microflora in broiler chickens. Food and Agricultural Immunology, 2018, 29(1): 859-869 
(doi: 10.1080/09540105.2018.1463972).

53. Cui Y.M., Wang J., Lu W., Zhang H.J., Wu S.G., Qi G.H. Effect of dietary supplementation with Moringa oleifera leaf on performance, meat quality, and oxidative stability of meat in broilers. Poultry Science, 2018, 97(8): 2836-2844 (doi: 10.3382/ps/pey122).

54. Kumar P., Patra A.K., Mandal G.P., Debnath B.C. Carcass characteristics, chemical and fatty acid composition and oxidative stability of meat from broiler chickens fed black cumin (Nigella sativa) seeds. J. Anim. Physiol. Anim. Nutr., 2018, 102(3): 769-779 (doi: 10.1111/jpn.12880).

55. Ubua J.A., Ozung P.O., Inagu P.G., Aboluja B.A. Blood characteristics of broiler chickens as influenced by dietary inclusion of neem (Azadirachta indica) leaf meal. Canadian Journal of Agriculture and Crops, 2018, 3(2): 72-80 (doi: 10.20448/803.3.2.72.80).

56. Patel A.P., Bhagwat S.R., Pawar M.M., Prajapati K.B., Chauhan H.D., Makwana R.B. Evaluation of Emblica officinalis fruit powder as a growth promoter in commercial broiler chickens. Veterinary World, 2016, 9(2): 207-210 (doi: 10.14202/vetworld.2016.207-210).

57. Sizova E., Miroshnikov S., Lebedev S., Kudasheva A., Ryabov N. To the development of innovative mineral additives based on alloy of $\mathrm{Fe}$ and $\mathrm{Co}$ antagonists as an example. Agricultural Biology [Sel'skokhozyaistvennaua Biologiya], 2016, 51(4): 553-562. (doi: 10.15389/agrobiology.2016.4.553eng).

58. Nworgu F.C., Ogungbenro S.A., Solesi K.S. Performance and some blood chemistry indices of broiler chicken served fluted pumpkin (Telfaria occidentalis) leaves extract supplement. AmericanEurasian J. Agric \& Environ. Sci., 2007, 2(1): 90-98.

59. Alagawany M., El-Hack M.E., Farag M.R., Sachan S., Karthik K., Dhama K. The use of probiotics as eco-friendly alternatives for antibiotics in poultry nutrition. Environmental Science and Pollution Research, 2018, 25(11): 10611-10618 (doi: 10.1007/s11356-018-1687-x).

60. Gotep J.G., Tanko J.T., Forcados G.E., Muraina I.A., Ozele N., Dogonyaro B.B., Oladipo O.O., Makoshi M.S., Akanbi O.B., Kinjir H., Samuel A.L., Onyiche T.E., Ochigbo G.O., Aladelokun O.B., Ozoani H.A., Viyoff V.Z., Dapuliga C.C., Atiku A.A., Okewole P.A., Shamaki D., Ahmed M.S., Nduaka C.I. Therapeutic and safety evaluation of combined aqueous extracts of azadirachta indica and Khaya senegalensis in chickens experimentally infected with eimeria oocysts. Journal of Parasitology Research, 2016, 2016: 4692424 (doi: 10.1155/2016/4692424).

61. Heymsfield S.B., Wadden T.A. Mechanisms, pathophysiology, and management of obesity. New England Journal of Medicine, 2017, 376(3): 254-266 (doi: 10.1056/NEJMra1514009). 